\title{
Childhood fish oil supplementation modifies associations between traffic related air pollution and allergic sensitisation
}

Anna L. Hansell ${ }^{1,2^{*}}$, Ioannis Bakolis ${ }^{1,3,4}$, Christine T. Cowie ${ }^{5,6,7}$, Elena G. Belousova ${ }^{7}$, Kitty Ng ${ }^{7}$, Christina Weber-Chrysochoou ${ }^{7}$, Warwick J. Britton ${ }^{8}$, Stephen R. Leeder ${ }^{9}$, Euan R. Tovey ${ }^{7}$, Karen L. Webb ${ }^{9,10}$, Brett G. Toelle $e^{7,11}$ and Guy B. Marks $s^{6,7,12}$

\begin{abstract}
Background: Studies of potential adverse effects of traffic related air pollution (TRAP) on allergic disease have had mixed findings. Nutritional studies to examine whether fish oil supplementation may protect against development of allergic disease through their anti-inflammatory actions have also had mixed findings. Extremely few studies to date have considered whether air pollution and dietary factors such as fish oil intake may interact, which was the rationale for this study.

Methods: We conducted a secondary analysis of the Childhood Asthma Prevention Study (CAPS) birth cohort, where children were randomised to fish oil supplementation or placebo from early life to age 5 years. We examined interactions between supplementation and TRAP (using weighted road density at place of residence as our measure of traffic related air pollution exposure) with allergic disease and lung function outcomes at age 5 and 8 years.

Results: Outcome information was available on approximately 400 children ( $70 \%$ of the original birth cohort). Statistically significant interactions between fish oil supplementation and TRAP were seen for house dust mite (HDM), inhalant and all-allergen skin prick tests (SPTs) and for HDM-specific interleukin-5 response at age 5. Adjusting for relevant confounders, relative risks (RRs) for positive HDM SPT were RR 1.74 (95\% Cl 1.22-2.48) per 100 m local road or $33.3 \mathrm{~m}$ of motorway within $50 \mathrm{~m}$ of the home for those randomised to the control group and 1.03 (0.76-1.41) for those randomised to receive the fish oil supplement. The risk differential was highest in an analysis restricted to those who did not change address between ages 5 and 8 years. In this sub-group, supplementation also protected against the effect of traffic exposure on pre-bronchodilator $\mathrm{FEV}_{1} / \mathrm{FVC}$ ratio.
\end{abstract}

Conclusions: Results suggest that fish oil supplementation may protect against pro-allergic sensitisation effects of TRAP exposure. Strengths of this analysis are that supplementation was randomised and independent of TRAP exposure, however, findings need to be confirmed in a larger experimental study with the interaction investigated as a primary hypothesis, potentially also exploring epigenetic mechanisms. More generally, studies of adverse health effects of air pollution may benefit from considering potential effect modification by diet and other factors.

(Continued on next page)

\footnotetext{
* Correspondence: a.hansell@imperial.ac.uk

${ }^{1}$ MRC-PHE Centre for Environment and Health, Department of Epidemiology and Biostatistics, School of Public Health, Imperial College London, St Mary's Campus, Norfolk Place, London W2 1PG, UK

${ }^{2}$ Public Health and Primary Care Directorate, Imperial College Healthcare NHS

Trust, London, UK

Full list of author information is available at the end of the article
} 
(Continued from previous page)

Trial registration: Australia New Zealand Clinical Trial Registry. www.anzctr.org.au Registration: ACTRN12605000042640, Date: 26th July 2005. Retrospectively registered, trial commenced prior to registry availability.

Keywords: Allergic sensitisation, Air pollution, PUFAs, Fish oil, Lung function, Children, Birth cohort

\section{Background}

A number of environmental health studies have found associations between ambient air pollution exposure and allergen sensitisation [1-3] although some studies have not, most notably a meta-analysis of five European cohorts in the European Study of Cohorts and Air Pollution Effects (ESCAPE) [4]. Meanwhile, nutritional studies have examined whether fish oil intake may protect against development of allergic disease through their known antiinflammatory actions [5]. Previous randomized controlled trials of fish oil supplementation in pregnancy, lactation and from birth [6-13] have had mixed findings without consistently observed benefits of supplementation on either asthma or allergy development in childhood. Extremely few studies to date have considered whether dietary factors may modify impacts of air pollution, which could be a potential explanation for inconsistent findings in both air pollution and fish oil supplementation studies.

In this study we investigated the hypothesis that the risk of allergic sensitisation in relation to traffic related air pollution (TRAP) exposure in childhood would be modified (reduced) by fish oil supplementation. We conducted a secondary analysis of the Childhood Asthma Prevention Study (CAPS), set up as a randomised controlled trial investigating whether fish oil supplementation or house dust mite (HDM) exposure reduction implemented from the first year of life to age 5 years reduced the risk of development of asthma or atopy in children at high risk of developing these due to a family history of asthma [14]. No effect of either intervention was demonstrated at either 5 [15] or 8 [7] years. We have demonstrated, in a subsequent cross-sectional analysis of the whole cohort participating at age 8 years [16], that children living in homes with higher weighted road density, as a marker of TRAP, had higher probabilities of allergic sensitisation to house dust mite and allergic rhinitis and also showed small decrements in mid-expiratory flows.

\section{Methods}

\section{Randomisation in the original RCT}

Six hundred sixteen children born in 1997-2000 were included in the original RCT. Recruitment took place before birth - pregnant women whose child would be at high risk of developing asthma, because of a parent or a sibling with a current diagnosis of asthma or with frequent wheeze, were recruited from antenatal clinics of six hospitals in Sydney, Australia (see Additional file 1).
In the 'active supplement intervention' group, children were given capsules of $500 \mathrm{mg}$ of tuna fish oil added to infant formula from birth, or if breast fed, from age 6 months along with monounsaturated cooking oils and fat spreads, which were commenced when the child started solid foods and were continued to the age of 5 years. The tuna fish oil contained $37 \%$ omega- 3 polyunsaturated and $6 \%$ omega- 6 fatty polyunsaturated acids, $24 \%$ monounsaturated acids, $28 \%$ saturated fatty acids and $5 \%$ minor fatty acids. The control group were supplied with oils and margarines designed to maintain the low omega- 3 and high omega- 6 intake seen in the Australian population, as detailed elsewhere $[14,15]$. Compliance with supplementation was checked regularly and plasma levels of omega- 3 were found to be significantly higher in the active supplement intervention group and plasma omega-6 levels significantly lower compared with controls at age 18 month, 3 year and 5 year clinical follow-ups [15].

\section{Weighted road density exposure assignment}

Weighted road density (WRD) at place of residence was used as an indicator of exposure to TRAP, using a method designed to predict air pollution for areas where air quality monitoring and traffic count data were not available [17]. Address was only retained electronically from age 8 years onwards but not from birth. Paper records were hand searched to identify addresses from ages 5 to to 8 years for 129 participants who indicated at age 8 years that they had moved since the age 5 year follow-up. Timing of moving house could not be reliably inferred and address records for ages $<5$ years were incomplete so it was not possible to construct a lifetime residential history. Addresses were geocoded using the Geographic National Address File (GNAF) with additional investigation by hand using Google Maps; 99.4\% of addresses available were successfully geocoded.

Each study subject still residing in New South Wales was assigned a WRD score comprising the weighted sum of the lengths of road within $50 \mathrm{~m}$ radius of the property centroid of the main place of residence at the time of the clinic visits at age 5 and 8 years. As described previously [17], motorways, arterial roads and primary roads were given a weighting of 3 , distributor roads a weighting of 2 and local roads given a weighting of 1 . Radii of $50 \mathrm{~m}$ were chosen given that concentrations of nitrogen dioxide $\left(\mathrm{NO}_{2}\right)$, often used as a marker 
of TRAP, have been shown to fall rapidly within that distance from roads [18] and because our previous work showed that WRD within $50 \mathrm{~m}$ of home, was associated with an increased probability of having positive HDM SPT and HDM specific IgE, with doctor-diagnosed allergic rhinitis and small decreases of pre-and post- bronchodilator mid-expiratory flow measures [16].

\section{Outcome assessment}

Questionnaires were administered by nurses and obtained information on symptoms, diagnosed asthma and allergic rhinitis, and various environmental factors and confounders. Clinical assessment at both age 5 and 8 years included height, weight, allergen skin prick testing (SPT, classified positive if weal $\geq 3 \mathrm{~mm}$ at $10 \mathrm{~min}$ ), blood samples for total IgE, interleukin (IL-) 5 and IL-10 in vitro T cell cytokine responses to HDM extract (responders $\geq 10 \mathrm{pg} / \mathrm{ml}$ ), and lung function (Forced Expiratory Volume in one second $\left(\mathrm{FEV}_{1}\right)$, Forced Vital Capacity (FVC), Forced Expiratory Flow at $50 \%$ of $\mathrm{FVC}\left(\mathrm{FEF}_{50}\right)$, Forced Expiratory Flow at $25-75 \%$ of FVC ( $\left.\mathrm{FEF}_{25-75}\right)$, Peak Expiratory Flow (PEF)). Spirometric lung function was measured pre- and post- administration of bronchodilator (salbutamol $200 \mu \mathrm{g}$ ). At the age 8 years assessment, methacholine challenge test was performed in all consenting children with baseline $\mathrm{FEV}_{1}>70 \%$ predicted. The measurement of bronchodilator response was conducted on a different day from all other clinical measurements. (For further details please see Additional file 1).

\section{Ethics}

Informed written consent was given by the parents of participating children and the study was approved by the $\mathrm{Hu}-$ man Research Ethics Committees of the University of Sydney \#12-2004/7954, Children's Hospital at Westmead HREC96/7/4.17(154), Sydney South West Area Health Services \#96/80 and Sydney Local Health District \#08/ $\mathrm{RPAH} / 472$.

\section{Statistical analysis}

Associations between WRD at place of residence and binary allergic and respiratory outcomes at age 5 and age 8 years (SPTs, asthma, wheeze, allergic rhinitis, eczema, and interleukins) were investigated using a random intercept Poisson model with robust error variance $[16,19]$. A random intercept linear regression model was used to analyse the effect of WRD on lung function $\left(\mathrm{FEV}_{1}, \mathrm{FVC}\right.$ and $\mathrm{FEV}_{1} / \mathrm{FVC}$ ratio) and total IgE. Lung function analyses were conducted on log-transformed variables and included (a priori defined) covariates of age at testing, weight and height. Effect modification of the association of the above allergic and respiratory outcomes with randomisation to fish oil supplementation (yes/no) was assessed by the inclusion of an interaction term in the random intercept Poisson and linear models. Relative Risks
(RRs) provided are expressed as increase in risk per unit increase in weighted road density, representing $100 \mathrm{~m}$ local road or $33.3 \mathrm{~m}$ of motorway within $50 \mathrm{~m}$ of the home. Associations between age 5 to age 8 years were not statistically significantly different from each other ( $p$ values of interaction terms between fish oil supplementation, weighted road density and time (age 5 and age 8 ) for questionnaire and clinical outcomes $>0.05$, data not shown). Therefore, we conducted a repeated measures analysis using exposure and outcome observations from age 5 and age 8 years to increase statistical power. We also restricted analyses to those who had not moved house between age 5 and 8 years who might be expected to have less exposure misclassification for exposure to TRAP.

Further sensitivity analyses were conducted stratified by atopy (any positive SPT at age 8 years) because our previous analyses not taking account of randomisation suggested atopic children might be more sensitive to TRAP [16].

All analyses adjusted for the following potential confounders identified a priori: sex, ethnicity, environmental tobacco exposure during pregnancy and childhood, breast-feeding to age 6 months, current or previous dog or cat ownership, gas cooking, parental education. Analyses were performed using STATA 13.1.

\section{Results}

There were 616 children in the original birth cohort and 560 remained living in New South Wales with an address at age 8 years that could be geocoded. At age 5 and age 8 years respectively there were 418 ( $74 \%$ of 560$)$ and 419 (75\%) children with questionnaire information on current asthma symptoms; 409 (73\%) and 382 (68\% of 560) with SPTs; and $382(68 \%)$ and 410 (73\%) with lung function tests. At age 8 years, 121 (28.9\%) of the 419 children with questionnaire information and 104 (27.2\%) of the 382 children with SPTs had moved house since age 5 years. A flow chart of the sample selection is shown in Fig. 1.

Characteristics of the children at age 5 and age 8 are presented in Table 1. At age 5 years, HDM was the most common allergen children were sensitised to: $29 \%$ had positive SPT. The next most common allergens were grasses ( $11 \%$ with positive SPTs). Sensitisation was much lower $(<10 \%)$ for ingested (food) allergens than inhalant allergens (see Table 1 for definitions). At age 5 years, $31 \%$ had wheezed in the last 12 months and $27 \%$ had ever had doctor diagnosed asthma. Respective percentages for age 8 years were HDM SPT 36\%, wheeze in last 12 months $27 \%$, and ever doctor diagnosed asthma $41 \%$. Half (51\%) of the children had been randomised to fish oil supplementation. Analysis of plasma fatty acids for omega3/6 ratio at the clinic visit showed slightly higher mean ratios in those in the supplementation group at age 5 but not at age 8 years. Distribution of confounders is shown in Additional file 2: Table S1. 


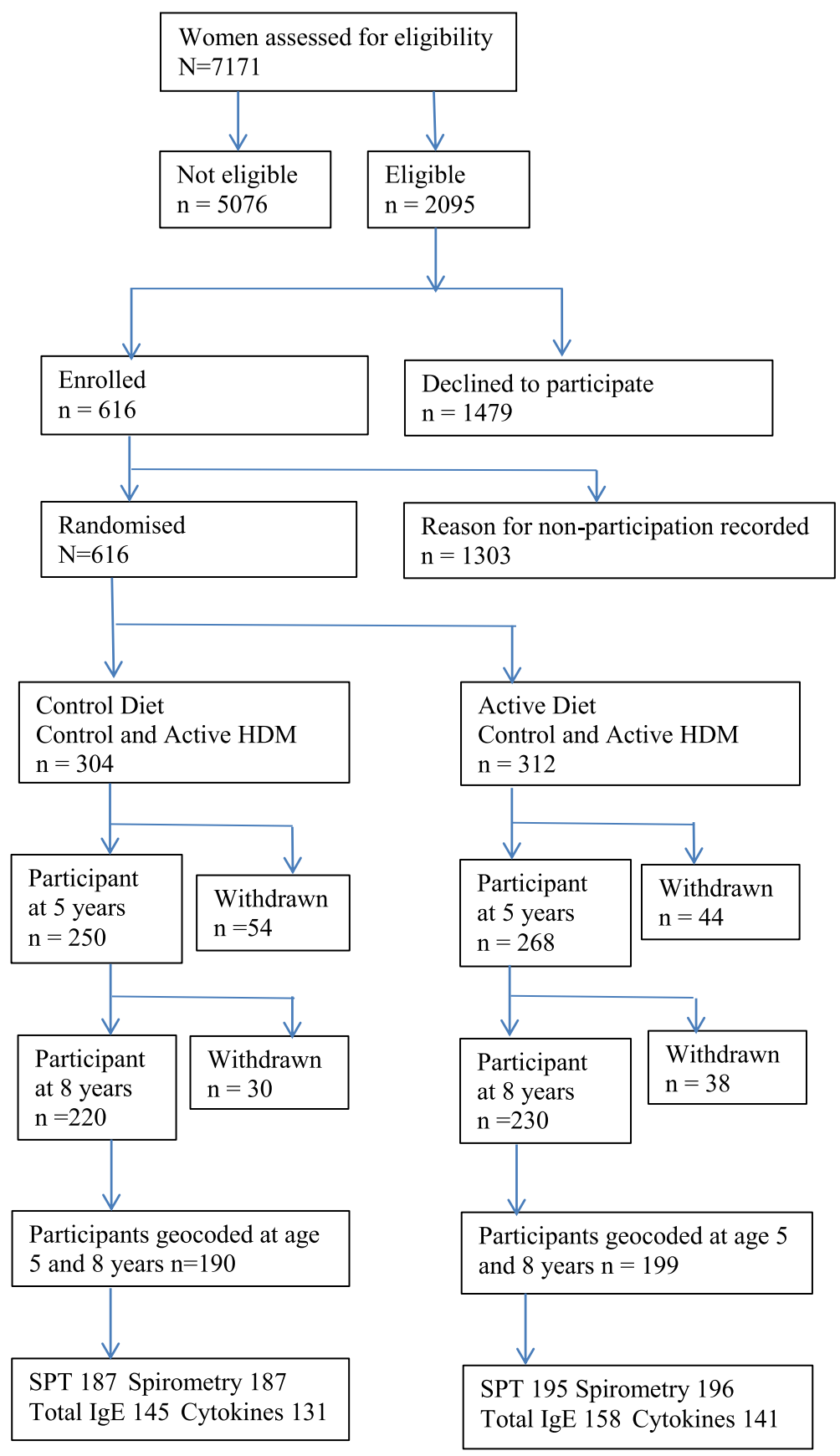

Fig. 1 Flow-chart of CAPS study participants with respect to original randomisation

\section{Analysis for age 5 years and for age $\mathbf{8}$ years}

Interactions between fish oil supplementation and WRD were suggested for HDM, inhalant and all-allergen SPTs and for HDM-specific IL-5 (Table 2) at age 5 years, but not for other outcomes or for lung function tests (Tables 2 \& 3). Relative risks of positive skin prick test to HDM were RR 1.74 (95\% CI 1.22-2.48) per $100 \mathrm{~m}$ local road or $33.3 \mathrm{~m}$ of motorway within $50 \mathrm{~m}$ of home for those randomised to the control group and $1.03(0.76-1.41)$ for those randomised to the active supplement intervention. For HDM-specific IL-5 the RR was 1.83 (1.21-2.76) for the control group and $0.653(0.38-1.11)$ in the active supplement intervention group. Results for age 8 years showed statistical significance for the interaction term for both IL-5 and IL-10 (Additional file 2: Tables S2 and S3), but with lower RRs (IL-5 RR 1.52 (1.16-2.00)). 
Table 1 Allergic sensitisation, self-reported allergic disease, lung function testing, weighted road density and potential confounders at age 5 and 8 years

\begin{tabular}{|c|c|c|c|c|}
\hline & At age 5 years & & At age 8 years & \\
\hline Positive skin prick tests (Skin prick test $>3 \mathrm{~mm}$ ) & Number (\%) & $n$ & Number (\%) & $n$ \\
\hline Any of 11 inhalant and food allergens ${ }^{a}$ & 151 (36.9\%) & 409 & $173(45.3 \%)$ & 382 \\
\hline Inhalant allergen ${ }^{\mathrm{b}}$ & $145(35.4 \%)$ & 409 & $170(44.5 \%)$ & 382 \\
\hline Ingested allergen ${ }^{c}$ & $25(6.1 \%)$ & 409 & $30(7.9 \%)$ & 382 \\
\hline House dust mite (HDM) & $120(29.3 \%)$ & 409 & $137(35.9 \%)$ & 382 \\
\hline Ryegrass & $43(10.5 \%)$ & 409 & $69(18.1 \%)$ & 381 \\
\hline Grass mix & $43(10.5 \%)$ & 409 & $51(13.4 \%)$ & 380 \\
\hline Alternaria tenuis & $29(7.1 \%)$ & 409 & $43(9.7 \%)$ & 380 \\
\hline Cockroach & $18(4.4 \%)$ & 409 & $18(4.7 \%)$ & 381 \\
\hline Cat dander & $16(4.5 \%)$ & 409 & $23(4.5 \%)$ & 382 \\
\hline \multicolumn{5}{|l|}{ Cytokines and total lgE } \\
\hline HDM specific IL-5 responder & $78(25.4 \%)$ & 307 & $78(30.23 \%)$ & 258 \\
\hline HDM specific IL-10 responder & $150(51.1 \%)$ & 293 & $121(46.7 \%)$ & 281 \\
\hline Total lgE (kU/L) & Median:70 IQR(25-186) & 341 & Median:1 18 IQR(37-392) & 303 \\
\hline \multicolumn{5}{|l|}{ Questionnaire variables } \\
\hline Doctor-diagnosed asthma & $114(27.2 \%)$ & 418 & $119(28.40 \%)$ & 419 \\
\hline Ever Doctor-diagnosed Asthma & $141(33.6 \%)$ & 419 & $170(40.5 \%)$ & 419 \\
\hline Wheeze in last 12 months & $130(31.1 \%)$ & 418 & $114(27.2 \%)$ & 419 \\
\hline Wheeze in the last 12 months + asthma diagnosis & $83(19.8 \%)$ & 418 & $91(21.7 \%)$ & 419 \\
\hline Cough in last 12 months at least four times & $143(34.2 \%)$ & 418 & $101(24.1 \%)$ & 419 \\
\hline Doctor diagnosed allergic rhinitis & $23(5.5 \%)$ & 418 & $52(12.4 \%)$ & 419 \\
\hline Doctor diagnosed eczema & $119(28.47 \%)$ & 418 & $129(30.7 \%)$ & 419 \\
\hline Eczema in the last 12 months & $92(22.1 \%)$ & 416 & $58(14.3 \%)$ & 405 \\
\hline Spirometry & Mean (SD) & N & Mean (SD) & N \\
\hline $\mathrm{FEV}_{1}$ pre bronchodilator $\%$ predicted & $115.8 \%(17.7)$ & 328 & $100.1 \%(11.8)$ & 396 \\
\hline FVC pre bronchodilator \% predicted & $124.3 \%(20.3)$ & 323 & $98.9 \%(11.6)$ & 390 \\
\hline $\mathrm{FEV}_{1}$ post bronchodilator $\%$ predicted & $120.0 \%(18.4)$ & 323 & $105.9 \%(11.1)$ & 392 \\
\hline FVC post bronchodilator $\%$ predicted & $128.2 \%(19.7)$ & 323 & $99.5 \%(10.6)$ & 386 \\
\hline $\mathrm{FEV}_{1} / \mathrm{FVC}$ ratio pre bronchodilator & $0.93(0.06)$ & 328 & $0.89(0.07)$ & 391 \\
\hline $\mathrm{FEV}_{1} / \mathrm{FVC}$ ratio post bronchodilator & $0.93(0.06)$ & 328 & $0.93(0.05)$ & 387 \\
\hline pre Peak Expiratory Flow (PEF) & $2.28(0.47)$ & 326 & $203(37.1)$ & 410 \\
\hline post Peak Expiratory Flow (PEF) & $2.33(0.53)$ & 321 & $211(38.2)$ & 406 \\
\hline Pre forced expiratory flow at $50 \%$ vital capacity $\left(\mathrm{FEF}_{50}\right)$ & $1.60(0.41)$ & 326 & $2.18(0.55)$ & 410 \\
\hline Post forced expiratory flow at $50 \%$ vital capacity $\left(\mathrm{FEF}_{50}\right)$ & $1.77(0.51)$ & 321 & $2.51(0.53)$ & 406 \\
\hline Pre forced expiratory flow at mid-expiratory phase $\left(\mathrm{FEF}_{25-75}\right)$ & $1.46(0.37)$ & 326 & $2.11(0.43)$ & 410 \\
\hline Post forced expiratory flow at mid-expiratory phase $\left(\mathrm{FEF}_{25-75}\right)$ & $1.61(0.46)$ & 321 & $2.35(0.43)$ & 406 \\
\hline Exposure & Mean (SD) & N & Mean (SD) & N \\
\hline $\begin{array}{l}\text { Weighted road density within } 50 \mathrm{~m} \text { of home, where one unit } \\
\text { represents } 100 \mathrm{~m} \text { local road or } 33.3 \mathrm{~m} \text { of motorway }\end{array}$ & $1.04(0.6)$ & 390 & $1.1(0.6)$ & 389 \\
\hline \multirow{2}{*}{$\begin{array}{l}\text { Mean Omega3:Omega6 ratio (fish oil supplemented vs. } \\
\text { non-supplemented (p-value significance)) }\end{array}$} & 0.18 vs. $0.14^{(* * *)}$ & 367 & 0.15 vs. $0.15^{(\mathrm{NS})}$ & 314 \\
\hline & Number (\%) & $\mathrm{N}$ & Number (\%) & N \\
\hline Fish oil supplementation at age 5 years & $214(51 \%)$ & 419 & $214(51 \%)$ & 419 \\
\hline Urban environment & $392(93.7 \%)$ & 418 & 421 (91.9\%) & 458 \\
\hline
\end{tabular}

${ }^{a}$ Any of egg white, egg yolk, salmon, tuna, peanuts, D. Pteronyssinus, cat dander, cockroach, alternaria, rye grass, grass mix, dog hair, aspergillus

${ }^{\mathrm{b}}$ Any of $D$. Pteronyssinus, cat dander, cockroach, rye grass, grass mix, alternaria, dog hair, aspergillus

'Any of egg white, egg yolk, salmon, tuna, peanuts

***t-test $p$-value $<0.001$

${ }^{\mathrm{Ns}}$ t-test $p$-value $>0.1$ 
Table 2 Associations of selected allergic and respiratory outcomes at age 5 years in relation to weighted road density within a $50 \mathrm{~m}$ radius of home adjusted for potential confounders stratified by fish oil supplementation

\begin{tabular}{|c|c|c|c|c|c|c|c|c|c|}
\hline \multirow[t]{2}{*}{ Total lgE } & \multicolumn{4}{|c|}{ No fish oil supplementation } & \multicolumn{4}{|c|}{ Fish oil supplementation } & \multirow{2}{*}{$\begin{array}{l}p \text {-value for } \\
\text { interaction }\end{array}$} \\
\hline & $\mathrm{N}$ & $\begin{array}{l}\text { Mean } \\
\text { difference }\end{array}$ & $95 \% \mathrm{Cl}$ & $p$-value & $\mathrm{N}$ & $\begin{array}{l}\text { Mean } \\
\text { difference }\end{array}$ & $95 \% \mathrm{Cl}$ & $p$-value & \\
\hline Total lgE (kU/L) & 165 & -0.023 & $-0.29-0.34$ & 0.760 & 161 & -0.18 & $-0.34-0.20$ & 0.785 & 0.291 \\
\hline Questionnaire variables & & $\mathrm{RR}$ & & & & RR & & & \\
\hline Doctor diagnosed asthma & 186 & 0.91 & $0.58-1.43$ & 0.689 & 186 & 1.18 & $0.82-1.71$ & 0.370 & 0.384 \\
\hline Ever had doctor diagnosed asthma & 186 & 0.91 & $0.63-1.29$ & 0.556 & 186 & 1.10 & $0.84-1.44$ & 0.746 & 0.423 \\
\hline Wheeze in the last 12 months & 186 & 1.18 & $0.81-1.72$ & 0.387 & 186 & 1.05 & $0.79-1.39$ & 0.724 & 0.664 \\
\hline Wheeze in the last 12 months \& asthma & 186 & 1.08 & $0.60-1.95$ & 0.798 & 186 & 0.90 & $0.59-1.38$ & 0.641 & 0.770 \\
\hline Cough more than 4 times in the last 12 months & 186 & 1.14 & $0.81-1.59$ & 0.459 & 186 & 1.20 & $0.95-1.53$ & 0.132 & 0.794 \\
\hline Doctor diagnosed Eczema & 186 & 1.13 & $0.78-1.65$ & 0.514 & 186 & 1.43 & $1.10-1.87$ & 0.007 & 0.631 \\
\hline Eczema in the last 12 months & 185 & 1.46 & $1.01-2.11$ & 0.043 & 186 & 1.34 & $0.96-1.87$ & 0.085 & 0.882 \\
\hline Doctor diagnosed allergic rhinitis & 186 & 1.27 & $0.61-2.64$ & 0.528 & 186 & 3.44 & $1.82-6.47$ & 0.000 & 0.969 \\
\hline \multicolumn{10}{|l|}{ Skin prick tests } \\
\hline Any of 11 inhalant and food allergens & 181 & 1.34 & $1.00-1.80$ & 0.054 & 186 & 0.90 & $0.67-1.21$ & 0.493 & 0.042 \\
\hline Inhalant allergen & 181 & 1.40 & $1.04-1.89$ & 0.029 & 186 & 0.91 & $0.67-1.23$ & 0.544 & 0.027 \\
\hline Ingested allergen & 181 & 0.51 & $0.10-2.63$ & 0.424 & 186 & 1.28 & $0.55-2.99$ & 0.571 & 0.695 \\
\hline House dust mite (HDM) & 181 & 1.74 & $1.22-2.48$ & 0.002 & 186 & 1.03 & $0.76-1.41$ & 0.840 & 0.015 \\
\hline Alternaria tenuis & 181 & 0.27 & $0.11-0.64$ & 0.003 & 186 & 0.96 & $0.51-1.82$ & 0.906 & 0.567 \\
\hline Grass mix & 181 & 1.34 & $0.71-2.55$ & 0.368 & 186 & 1.04 & $0.56-1.92$ & 0.910 & 0.963 \\
\hline Rye Grass & 181 & 1.33 & $0.70-2.53$ & 0.382 & 185 & 1.08 & $0.66-1.78$ & 0.761 & 0.906 \\
\hline \multicolumn{10}{|l|}{ HDM-specific cytokines } \\
\hline $\mathrm{IL}-5$ (> $10 \mathrm{pg} / \mathrm{ml})$ & 139 & 1.83 & $1.21-2.76$ & 0.004 & 139 & 0.65 & $0.38-1.11$ & 0.117 & 0.003 \\
\hline $\mathrm{IL}-10$ (> $10 \mathrm{pg} / \mathrm{ml})$ & 131 & 1 & $0.83-1.22$ & 0.969 & 133 & 0.98 & $0.83-1.16$ & 0.817 & 0.981 \\
\hline
\end{tabular}

All models are adjusted for sex, father's education, mother's education, environmental tobacco smoke exposure, breastfed to 6 months, any dog owned by 5 or 8 years, any cat owned by 5 or 8 years, maternal smoking in pregnancy, gas cooking at home

Interaction term of fish oil supplementation with weighted road density was added as a separate term into a Poisson model

Mean difference, Relative Risks (RRs) and 95\% confidence intervals $(95 \% \mathrm{Cl})$ represent increase in risk per unit increase in weighted road density, representing $100 \mathrm{~m}$ local road or $33.3 \mathrm{~m}$ of motorway within $50 \mathrm{~m}$ of the home. $\mathrm{N}=$ number of children

\section{Repeated measures analysis for age 5 and 8 years}

The repeated measures analysis that combined outcomes measured at ages 5 and age 8 years was suggestive of interactions for HDM-specific IL-5 (Additional file 2: Tables S4 and S5); again no effect was seen on lung function. When restricting the repeated measures analysis to those who did not move house between the age of 5 and 8 years, interactions between fish oil supplementation and weighted road density for positive SPT for HDM, inhalant and all-allergen SPTs and for HDM-specific IL-5 responses (Table 4) showed a similar pattern to that seen for age 5 years (Table 2) but with higher RRs. Specifically, for WRD and HDM SPT, the RR was 2.36 (1.34-4.14) for the control group and $0.97(0.67-1.42)$ for the 'active supplement intervention' group. Results for lung function (Table 5) suggested interaction for pre- but not post-bronchodilator $\mathrm{FEV}_{1} / \mathrm{FVC}$ ratio, with a $3 \%$ (5\% to $1 \%$ ) decrease in $\mathrm{FEV}_{1} / \mathrm{FVC}$ ratio for the control group but no effect among children in the 'active supplement intervention' group. Restricting analyses to those who were atopic did not suggest significant interaction for the supplement intervention (Additional file 2: Tables S6 and S7), but numbers in each cell were small.

\section{Discussion}

To examine our hypothesis that fish oil supplementation might modify adverse effects of TRAP, we conducted a secondary analysis of a RCT that had previously shown no effect overall of fish oil supplementation on incidence of asthma or allergic sensitisation [7]. Analyses suggested protective effect modification by randomisation group status on associations between WRD within $50 \mathrm{~m}$ of home and HDM sensitisation whether assessed by SPT or HDM-specific cytokine responses and on pre(but not post-) bronchodilator $\mathrm{FEV}_{1} / \mathrm{FVC}$ ratio. Impacts of the active supplement intervention, which included fish oil supplementation and provision of canola-based 
Table 3 Associations of lung function measurements at age 5 years in relation to weighted road density within a $50 \mathrm{~m}$ radius of home adjusted for potential confounders stratified by fish oil supplementation

\begin{tabular}{|c|c|c|c|c|c|c|c|c|c|}
\hline & \multicolumn{4}{|c|}{ No fish oil supplementation } & \multicolumn{4}{|c|}{ Fish oil supplementation } & \multirow{2}{*}{$\begin{array}{l}p \text {-value for } \\
\text { interaction }\end{array}$} \\
\hline & $\mathrm{N}$ & $\begin{array}{l}\text { Mean } \\
\text { Difference }\end{array}$ & $95 \% \mathrm{Cl}$ & $p$-value & $\mathrm{N}$ & $\begin{array}{l}\text { Mean } \\
\text { Difference }\end{array}$ & $95 \% \mathrm{Cl}$ & $p$-value & \\
\hline log (FEV1 pre bronchodilator $(L))$ & 154 & -0.04 & $-0.09-0.01$ & 0.083 & 147 & -0.04 & $-0.08-0.01$ & 0.100 & 0.760 \\
\hline log (FEV1 post bronchodilator (L)) & 151 & -0.03 & $-0.08-0.01$ & 0.150 & 146 & -0.03 & $-0.08-0.02$ & 0.188 & 0.808 \\
\hline $\log ($ FVC pre bronchodilator (L)) & 154 & -0.05 & $-0.10-0.01$ & 0.102 & 147 & -0.03 & $-0.08-0.01$ & 0.171 & 0.854 \\
\hline $\log ($ FVC post bronchodilator (L)) & 151 & -0.03 & $-0.08-0.03$ & 0.306 & 146 & -0.01 & $-0.06-0.04$ & 0.641 & 0.950 \\
\hline FEV1/FVC ratio pre bronchodilator & 154 & -0.05 & $-0.10-0.00$ & 0.037 & 147 & -0.03 & $-0.07-0.01$ & 0.126 & 0.932 \\
\hline FEV1/FVC ratio post bronchodilator & 151 & -0.04 & $-0.08-0.01$ & 0.102 & 146 & -0.03 & $-0.08-0.01$ & 0.175 & 0.908 \\
\hline pre Peak Expiratory Flow (PEF) & 154 & -0.05 & $-0.10-0.00$ & 0.073 & 147 & -0.03 & $-0.07-0.02$ & 0.237 & 0.903 \\
\hline post Peak Expiratory Flow (PEF) & 151 & -0.03 & $-0.07-0.02$ & 0.240 & 146 & -0.01 & $-0.05-0.03$ & 0.727 & 0.795 \\
\hline $\begin{array}{l}\text { Pre forced expiratory flow at } 50 \% \text { vital } \\
\text { capacity ( } \mathrm{FEF}_{50} \text { ) }\end{array}$ & 154 & 0 & $-0.02-0.01$ & 0.623 & 147 & -0.01 & $-0.02-0.01$ & 0.549 & 0.935 \\
\hline Post forced expiratory flow at $50 \%$ vital capacity $\left(\mathrm{FEF}_{50}\right)$ & 151 & -0.01 & $-0.02-0.01$ & 0.349 & 146 & -0.02 & $-0.04-0.00$ & 0.022 & 0.408 \\
\hline $\begin{array}{l}\text { Pre forced expiratory flow at mid-expiratory phase } \\
\left(\mathrm{FEF}_{25-75}\right)\end{array}$ & 102 & 5.30 & $-6.24-16.85$ & 0.364 & 99 & -0.32 & $-14.53-13.88$ & 0.964 & 0.386 \\
\hline $\begin{array}{l}\text { Post forced expiratory flow at mid-expiratory phase } \\
\left(\mathrm{FEF}_{25-75}\right)\end{array}$ & 100 & 6.23 & $-6.04-18.50$ & 0.316 & 98 & -0.49 & $-14.22-13.24$ & 0.944 & 0.410 \\
\hline
\end{tabular}

All models are adjusted for age at spirometry, height at spirometry, weight at spirometry, sex, father's education, mother's education, environmental tobacco smoke exposure, breastfed to 6 months, any dog owned by 5 or 8 years, any cat owned by 5 or 8 years, maternal smoking in pregnancy, gas cooking at home Interaction term of fish oil supplementation with weighted road density was added as a separate term into a random intercept Poisson model. Mean difference, Relative Risks (RRs) and $95 \%$ confidence intervals $(95 \% \mathrm{Cl}$ ) represent increase in risk per unit increase in weighted road density, representing $100 \mathrm{~m}$ local road or $33.3 \mathrm{~m}$ of motorway within $50 \mathrm{~m}$ of the home. $\mathrm{N}=$ number of children

oils and spreads, were also seen for all-allergen and inhalant allergen SPTs although these aggregate outcomes were strongly influenced by HDM-specific sensitisation status as this was the most common allergen to which participants were sensitised (Table 1).

Previously [16], we showed in this cohort of children with a family history of asthma or atopy that WRD within $50 \mathrm{~m}$ of home, an index of exposure to TRAP, was associated with the higher probability of having positive HDM SPT and HDM specific IgE, for doctor-diagnosed allergic rhinitis and small decreases of pre-and post- bronchodilator PEF, $\mathrm{FEF}_{50}$ and $\mathrm{FEF}_{25-75}$ [16], but we did not see associations with HDM-specific cytokine responses.

The aim of the fish oil supplementation was to alter the balance of $n-6$ and $n-3$ polyunsaturated fatty acids (PUFA), thus reducing the production of eicosanoid mediators produced from the n-6 PUFA arachidonic acid [20] that are key mediators of the airway inflammatory response. There may have been additional impacts on leukocyte chemotaxis, adhesion molecule expression and leukocyte-endothelial adhesive interactions, production of inflammatory cytokines and T-helper 1 lymphocyte activity [20], and reduction of inflammatory mediators [21].

It is difficult to conduct randomization of fish consumption, but observational studies of intake of fish in childhood have reported protective effects on asthma (four studies) [11] and allergic rhinitis [22]. Such studies have generally considered fish and fish oil intake in isolation and have not investigated co-factors or environmental agents that may have a role in the development of allergic disease.

The novel feature of this study is the assessment of environment-environment interactions that may, at least partly, explain inconsistencies in previous research that ignored these interactions. An RCT in children aged 6 years in South Africa found that long chain fish oil supplementation prevented increases in (primarily respiratory) infection associated with iron supplementation [23], which the authors attributed to iron-induced oxidative stress and inflammation. This is relevant here as TRAP produces inflammation that may in part relate to oxidative potential of metals included in the particulate fraction [18]. As well as potential for fish oils to reduce inflammatory responses $[5,20]$, other mechanisms by which fish oils may modify effects of TRAP include indirect influence on immune responses, via potential to influence the composition of the microbiome [24, 25].

Epigenetics may help provide a mechanism explaining the findings from this study. Traffic related air pollution has been shown to induce changes in methylation levels in genes relevant to asthma and allergic sensitisation [26, 27] and histone $\mathrm{H} 3$ modification [28], probably by increasing oxidative stress and pro-inflammatory responses. Epigenetic variations near and through the fatty acid desaturase $(F A D S)$ gene cluster account for variations in circulating 
Table 4 Repeated measures analysis of combined age 5 and 8 years: Associations of selected allergic and respiratory outcomes in relation to weighted road density within a $50 \mathrm{~m}$ radius of home stratified by fish oil supplementation and restricted to non-movers between age 5 and 8 years

\begin{tabular}{|c|c|c|c|c|c|c|c|c|c|}
\hline \multirow[t]{2}{*}{ Total lgE } & \multicolumn{4}{|c|}{ No fish oil supplementation } & \multicolumn{4}{|c|}{ Fish oil supplementation } & \multirow{2}{*}{$\begin{array}{l}p \text {-value for } \\
\text { interaction }\end{array}$} \\
\hline & $\mathrm{N}$ & $\begin{array}{l}\text { Mean } \\
\text { difference }\end{array}$ & $95 \% \mathrm{Cl}$ & $p$-value & $\mathrm{N}$ & $\begin{array}{l}\text { Mean } \\
\text { difference }\end{array}$ & $95 \% \mathrm{Cl}$ & $p$-value & \\
\hline Total lgE (kU/L) & 95 & -0.023 & $-0.28-0.24$ & 0.860 & 95 & -0.11 & $-0.36-0.15$ & 0.414 & 0.786 \\
\hline Questionnaire variables & & $\mathrm{RR}$ & & & & RR & & & \\
\hline Doctor diagnosed asthma & 126 & 1.11 & $0.66-1.89$ & 0.688 & 111 & 0.94 & $0.64-1.40$ & 0.781 & 0.763 \\
\hline Ever had doctor diagnosed asthma & 126 & 1.03 & $0.66-1.62$ & 0.889 & 111 & 0.78 & $0.54-1.16$ & 0.231 & 0.387 \\
\hline Wheeze in the last 12 months & 126 & 1.17 & $0.74-1.87$ & 0.499 & 111 & 0.87 & $0.64-1.21$ & 0.433 & 0.472 \\
\hline Wheeze in the last 12 months \& asthma & 126 & 1.23 & $0.65-2.36$ & 0.525 & 111 & 0.71 & $0.46-1.13$ & 0.155 & 0.308 \\
\hline Cough more than 4 times in the last 12 months & 126 & 1.26 & $0.83-1.90$ & 0.280 & 111 & 1.19 & $0.85-1.67$ & 0.308 & 0.955 \\
\hline Doctor diagnosed Eczema & 126 & 1.33 & $0.85-2.06$ & 0.209 & 111 & 1.25 & $0.85-1.83$ & 0.260 & 0.749 \\
\hline Eczema in the last 12 months & 125 & 1.57 & $0.88-2.78$ & 0.123 & 110 & 1.01 & $0.58-1.77$ & 0.973 & 0.467 \\
\hline Doctor diagnosed allergic rhinitis & 126 & 2.02 & $0.90-4.51$ & 0.086 & 111 & 2.38 & $1.01-5.62$ & 0.048 & 0.606 \\
\hline \multicolumn{10}{|l|}{ Positive Skin prick tests } \\
\hline Any of 11 inhalant and food allergens & 121 & 1.62 & $1.08-2.45$ & 0.021 & 107 & 0.75 & $0.53-1.09$ & 0.131 & 0.031 \\
\hline Inhalant allergen & 121 & 1.69 & $1.10-2.60$ & 0.016 & 107 & 0.77 & $0.54-1.11$ & 0.165 & 0.031 \\
\hline Ingested allergen & 121 & 1.49 & $0.45-4.89$ & 0.510 & 107 & 1.00 & $0.53-1.90$ & 0.996 & 0.800 \\
\hline House dust mite (HDM) & 121 & 2.36 & $1.34-4.14$ & 0.002 & 107 & 0.97 & $0.67-1.42$ & 0.902 & 0.026 \\
\hline Alternaria tenuis & 121 & 0.88 & $0.37-2.05$ & 0.762 & 107 & 0.71 & $0.38-1.35$ & 0.299 & 0.500 \\
\hline Grass mix & 121 & 1.57 & $0.63-3.92$ & 0.334 & 107 & 0.81 & $0.43-1.55$ & 0.535 & 0.406 \\
\hline Rye Grass & 121 & 1.73 & $0.78-3.86$ & 0.180 & 107 & 0.75 & $0.35-1.63$ & 0.475 & 0.206 \\
\hline \multicolumn{10}{|l|}{ HDM sensitization } \\
\hline $\mathrm{IL}-5$ (> $10 \mathrm{pg} / \mathrm{ml})$ & 83 & 2.05 & $1.26-3.32$ & 0.003 & 79 & 0.61 & $0.40-0.92$ & 0.0186 & $<0.001$ \\
\hline $\mathrm{IL}-10$ (> $10 \mathrm{pg} / \mathrm{ml})$ & 82 & 1 & $0.76-1.31$ & 0.996 & 77 & 0.87 & $0.72-1.03$ & 0.112 & 0.672 \\
\hline
\end{tabular}

All models are adjusted for sex, father's education, mother's education, environmental tobacco smoke exposure, breastfed to 6 months, any dog owned by 5 or 8 years, any cat owned by 5 or 8 years, maternal smoking in pregnancy, gas cooking at home

Interaction term of fish oil supplementation with weighted road density was added as a separate term into a random intercept Poisson model. Mean difference, Relative Risks (RRs) and 95\% confidence intervals $(95 \% \mathrm{Cl})$ represent increase in risk per unit increase in weighted road density, representing $100 \mathrm{~m}$ local road or $33.3 \mathrm{~m}$ of motorway within given radius of the home. $\mathrm{N}=$ number of children

and cellular long-chain PUFAs, the bioactive metabolites synthesised from dietary PUFAs [29]. Supplementation with dietary n-3 PUFA has been shown to be associated with DNA methylation of PUFA biosynthesis genes [30], leading to gene silencing of inflammatory pathways [31, 32]. In this study, the fatty acid dietary supplementation occurred during the first 5 years of life which coincides with a critical time in development of the immune system, therefore a hypothesis from our findings is that epigenetic modification induced by exposure to traffic related air pollution was protected against by epigenetic changes in children who received the dietary intervention.

Particular strengths of this study are that we conducted a post hoc analysis based on randomized allocation to a fish oil intervention. Compliance with the fish oil intervention was good in assessments conducted at 18 months, 3 and 5 years, verified by plasma omega-3/omega- 6 ratios
[15]. We did not conduct analyses based on ratios as these represent a snapshot at the time of clinic visit and may not be a good marker of long-term use of the supplement. Findings suggest it may be possible to modify sensitisation within the first 5 years of life, but, as the interventions were from birth until age 5 years, it was not possible to investigate optimal time windows for these effects within this time period. We conducted repeated measures analyses combining exposure and outcome observations from age 5 and age 8 years as there was no statistically significant difference between observed association patterns for outcomes at age 5 and age 8 years - the lack of difference suggests there was no important change in the protective effect of the supplement in the 3 year period following cessation of the active intervention.

Experimental studies have shown that diesel particulates act as adjuvants and increase sensitization to new 
Table 5 Repeated measures analysis of combined age 5 and 8 years: Associations of lung function measurements in relation to weighted road density within a $50 \mathrm{~m}$ radius of home and stratified by fish oil supplementation restricted to non-movers between age 5 and 8 years

\begin{tabular}{|c|c|c|c|c|c|c|c|c|c|}
\hline & \multicolumn{4}{|c|}{ No fish oil supplementation } & \multicolumn{4}{|c|}{ Fish oil supplementation } & \multirow{2}{*}{$\begin{array}{l}p \text {-value for } \\
\text { interaction }\end{array}$} \\
\hline & $\mathrm{N}$ & Mean Difference & $95 \% \mathrm{Cl}$ & $p$-value & $\mathrm{N}$ & Mean Difference & $95 \% \mathrm{Cl}$ & $p$-value & \\
\hline log(FEV1 pre bronchodilator $(\mathrm{L}))$ & 114 & -0.06 & $-0.11-0.02$ & 0.009 & 101 & 0 & $-0.04-0.04$ & 0.938 & 0.088 \\
\hline log(FEV1 post bronchodilator (L)) & 111 & -0.04 & $-0.08-0.00$ & 0.050 & 100 & -0.01 & $-0.05-0.02$ & 0.505 & 0.508 \\
\hline $\log ($ FVC pre bronchodilator (L)) & 113 & -0.03 & $-0.07-0.01$ & 0.200 & 99 & 0 & $-0.04-0.04$ & 0.997 & 0.680 \\
\hline $\log (F V C$ post bronchodilator (L)) & 110 & -0.01 & $-0.05-0.03$ & 0.587 & 98 & 0 & $-0.04-0.03$ & 0.846 & 0.843 \\
\hline FEV1/FVC ratio pre bronchodilator & 113 & -0.03 & $-0.05-0.01$ & 0.014 & 99 & 0 & $-0.02-0.02$ & 0.979 & 0.031 \\
\hline FEV1/FVC ratio post bronchodilator & 110 & -0.02 & $-0.04-0.01$ & 0.010 & 98 & -0.01 & $-0.02-0.01$ & 0.239 & 0.139 \\
\hline pre Peak Expiratory Flow (PEF) & 91 & 4.33 & $-4.09-12.75$ & 0.313 & 85 & -0.55 & $-7.14-6.04$ & 0.871 & 0.252 \\
\hline post Peak Expiratory Flow (PEF) & 90 & 8.46 & $-0.07-16.98$ & 0.051 & 84 & -2.57 & $-9.29-4.14$ & 0.453 & 0.056 \\
\hline $\begin{array}{l}\text { Pre forced expiratory flow at } 50 \% \text { vital } \\
\text { capacity ( } \mathrm{FEF}_{50} \text { ) }\end{array}$ & 91 & -0.09 & $-0.22-0.05$ & 0.227 & 85 & 0.01 & $-0.11-0.13$ & 0.893 & 0.380 \\
\hline $\begin{array}{l}\text { Post forced expiratory flow at } 50 \% \text { vital } \\
\text { capacity }\left(\mathrm{FEF}_{50}\right)\end{array}$ & 90 & -0.08 & $-0.23-0.08$ & 0.333 & 84 & -0.09 & $-0.22-0.04$ & 0.19 & 0.757 \\
\hline $\begin{array}{l}\text { Pre forced expiratory flow at mid- } \\
\text { expiratory phase }\left(\mathrm{FEF}_{25-75}\right)\end{array}$ & 91 & -0.07 & $-0.18-0.05$ & 0.270 & 85 & -0.02 & $-0.12-0.08$ & 0.743 & 0.747 \\
\hline $\begin{array}{l}\text { Post forced expiratory flow at mid- } \\
\left.\text { expiratory phase ( } \mathrm{FEF}_{25-75}\right)\end{array}$ & 90 & -0.03 & $-0.16-0.11$ & 0.701 & 84 & -0.08 & $-0.20-0.03$ & 0.161 & 0.369 \\
\hline
\end{tabular}

All models are adjusted for age at spirometry, height at spirometry, weight at spirometry, sex, father's education, mother's education, environmental tobacco smoke exposure, breastfed to 6 months, any dog owned by 5 or 8 years, any cat owned by 5 or 8 years, maternal smoking in pregnancy, gas cooking at home Interaction term of fish oil supplementation with weighted road density was added as a separate term into a random intercept Poisson model. Mean difference, Relative Risks (RRs) and $95 \%$ confidence intervals $(95 \% \mathrm{Cl})$ represent increase in risk per unit increase in weighted road density, representing $100 \mathrm{~m}$ local road or $33.3 \mathrm{~m}$ of motorway within $50 \mathrm{~m}$ of the home. $\mathrm{N}=$ number of children

allergens [33]. We used WRD at the place of residence as an indicator of exposure to TRAP. We did not have information on air pollutant concentrations or traffic count in the street of residence, but a previous evaluation of the WRD measure found this to be as strongly predictive of $\mathrm{NO}_{2}$ (measured by passive samplers) as was traffic volumes in a previous study in 2006-7 involving 38 monitoring sites in Sydney [17].

We found interactions between fish oil supplementation and HDM sensitization, and for pre- but not postbronchodilator FEV1/FVC ratio (in non-movers, i.e. reducing exposure misclassification bias), but not for symptoms. One of the issues with studying asthma symptoms (breathless, cough and wheeze) is that they may be caused by a heterogeneous range of conditions with different causes. For example, up to six distinct wheezing phenotypes have been suggested [34, 35]. Furthermore, symptoms are substantially affected by the use of medications. Hence, it is not particularly surprising the effect of one specific cause for symptoms, as tested here, might be difficult to detect. In contrast to symptoms, allergic sensitisation is a less heterogeneous outcome and is not influenced by treatment.

Our TRAP proxy measure, WRD within $50 \mathrm{~m}$ of each residence, was constructed and evaluated at the time children were aged 8 years. We were unable to retrospectively construct a lifetime residential history and as a result we were unable to look at the effect of the timing of TRAP exposure on the observed associations. We applied the WRD measure to place of residence at age 5 years (as TRAP exposures were expected to be similar over the 3 year period) and age 8 years, but this will have led to some exposure misclassification. We note that the effects were greater in the analyses that were restricted to non-movers between age 5 and age 8 years. This is consistent with the expected impact of a reduction in exposure misclassification.

This was a post hoc analysis of a relatively small cohort with potential selection bias related to both recruitment criteria and to selective drop-out of children. Just under a third of eligible pregnant mothers agreed to participate in the original RCT, however, this decision could not have been influenced by the child's as yet unknown asthma or allergic status. A further quarter of children had dropped out of the cohort by age 8 years; this was not related to exposure (WRD), but children who dropped out were more likely to have parents without a university education [16]. The latter might introduce bias that would reduce the size of an observed effect, as children of lower socio-economic status may be more likely to have a diet with a lower omega-3/omega- 6 ratio, and therefore benefit more from fish oil supplementation. Some of the associations may 
have been a result of chance, due to the number of analyses conducted. However, findings were consistent over various sensitivity analyses and between independent measures of HDM allergen sensitisation - SPT and cytokine responses. Further, the RCT was intentionally conducted in children expected to be at higher genetic likelihood of allergic sensitisation because of a family history of asthma, representing a group most likely to benefit from the intervention, but which may limit generalisability. Findings should be viewed as a hypothesis generating analysis and would need replication before inferring causality.

\section{Conclusions}

This study, conducted in children who were randomized to fish oil supplementation or placebo from birth to age 5 years, suggested that fish oil supplementation in early childhood may mitigate excess risk of allergic sensitisation associated with higher exposure to TRAP. This important interaction needs confirmation in independent cohorts and randomized trials, but the findings highlight the importance of studying environment-environment interactions.

\section{Additional files}

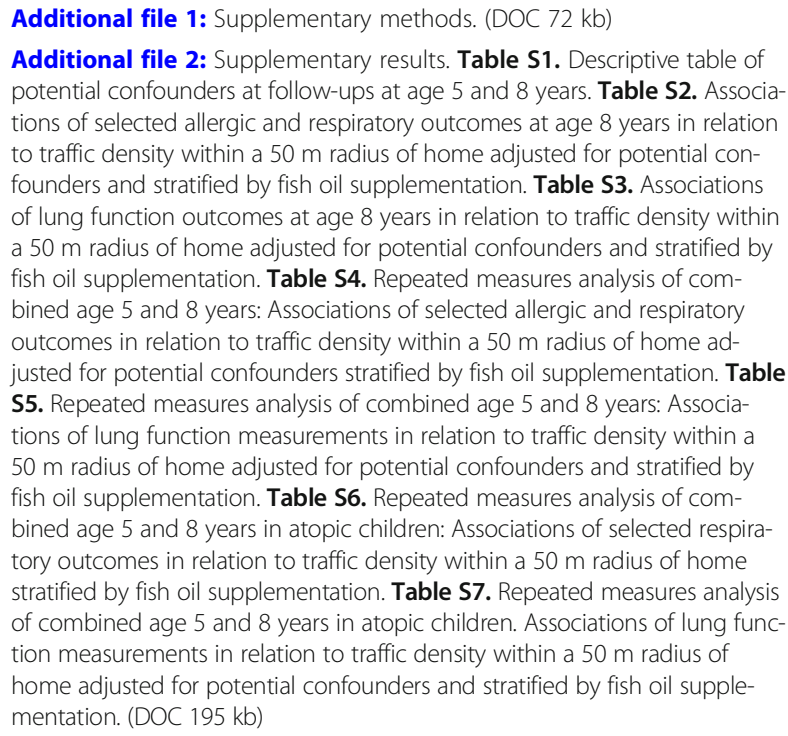

\section{Abbreviations}

CAPS: Childhood Asthma Prevention Study; ESCAPE: European Study of Cohorts and Air Pollution Effects; FEF $25-75$ : Forced Expiratory Flow at 25-75\% of FVC; $\mathrm{FEF}_{50}$ : Forced Expiratory Flow at $50 \%$ of FVC; FEV 1 : Forced Expiratory Volume in one second; FVC: Forced Vital Capacity; GNAF: Geographic National Address File; HDM: House Dust Mite; IL-10: Interleukin-10; IL5: Interleukin-5; $\mathrm{NO}_{2}$ : Nitrogen dioxide; PEF: Peak Expiratory Flow; PUFA: Polyunsaturated Fatty Acids; RR: Relative Risk; SPT: Skin Prick Test: TRAP: Traffic Related Air Pollution; WRD: Weighted Road Density

\section{Acknowledgements}

The Childhood Asthma Prevention Study Team who include the current authors, plus Catarina Almqvist, Rosario D Ampon, Julian Ayer, Tessa Bird,
Bronwyn K Brew, David Celermajer, Christopher T Cowell, Daniele Crisafulli, Sally Criss, Stella Davis, Wafaa Nabil Ezz, Samantha Forbes, Frances L Garden, Andrew S Kemp, Natalia Knezevic, William Krause, Craig M Mellis, Seema Mihrshahi, Mark Neumann, Jennifer K Peat, Andres Quinones-Lucio, Michael Skilton, Anne Tattam Carl H. Vanlaar, Nicola Vukasin, Craig Wainwright, Christina Weber-Chrysochoou, Ann J Woolcock, Jie Zhou. We thank Nectarios Rose for work on the road density measures.

\section{Funding}

This work was supported by the National Health and Medical Research Council of Australia, Cooperative Research Centre for Asthma, New South Wales Department of Health, Children's Hospital Westmead, University of Sydney, Faculty of Medicine, University of Sydney, Faculty of Medicine, Strategic Research Grant 2008. Contributions of goods and services were made by Allergopharma Joachim Ganzer KG Germany, John Sands Australia, Hasbro, Toll refrigerated, AstraZeneca Australia, and Nu-Mega Ingredients Pty Ltd. Goods were provided at reduced cost by Auspharm, Allersearch and Goodman Fielder Foods. AH was funded by Wellcome Trust grant number 075833 and a University of Sydney International Visiting Research Fellowship. The work of the UK Small Area Health Statistics Unit is funded by Public Health England as part of the MRC-PHE Centre for Environment and Health, funded also by the UK Medical Research Council (Medical Research Council-Public Health England Centre for Environment and Health Grant number: MR/L01341X/1). The funders had no role in study design, data collection and analysis, decision to publish, or preparation of the manuscript. loannis Bakolis is supported by the NIHR Biomedical Research Centre at South London and Maudsley NHS Foundation Trust and by the NIHR Collaboration for Leadership in Applied Health Research and Care South London at King's College Hospital NHS Foundation Trust

\section{Availability of data and materials}

Data are available from the authors upon reasonable request and with permission of Sydney Local Health District (RPAH Zone) Human Ethics Research Committee.

\section{Authors' contributions}

ALH and GBM conceived the original idea for the study. WJB, SRL, ERT, KW CTC, ALH, GBM contributed to study design. IB analyzed the data. CTC contributed to the geocoding and exposure analysis. EGB, KN, CW, BGT contributed to the data collection and geocoding. IB, WJB, SRL, ERT, KW, CTC $\mathrm{ALH}, \mathrm{BGT}$, GBM were involved in interpretation of the data. ALH and IB were major contributors to writing the manuscript. All authors read and approved the final manuscript.

\section{Ethics approval and consent to participate}

Informed written consent was given by the parents of participating children and the study was approved by the Human Research Ethics Committees of the University of Sydney, Children's Hospital at Westmead, and by Sydney South West Area Health Services.

Consent for publication

Not applicable.

\section{Competing interests}

The authors declare that they have no competing interests.

\section{Publisher's Note}

Springer Nature remains neutral with regard to jurisdictional claims in published maps and institutional affiliations.

\section{Author details}

${ }^{1}$ MRC-PHE Centre for Environment and Health, Department of Epidemiology and Biostatistics, School of Public Health, Imperial College London, St Mary's Campus, Norfolk Place, London W2 1PG, UK. ²Public Health and Primary Care Directorate, Imperial College Healthcare NHS Trust, London, UK. ${ }^{3}$ Department of Biostatistics and Health Informatics, Institute of Psychiatry, Psychology and Neuroscience, King's College London, De Crespigny Park, London, UK. ${ }^{4}$ Centre for Implementation Science, Health Services and Population Research Department, Institute of Psychiatry, Psychology and Neuroscience, King's College London, De Crespigny Park, London, UK. ${ }^{5}$ South West Sydney Clinical School, UNSW Australia, Sydney, NSW, Australia. ${ }^{6}$ Ingham Institute for 
Applied Medical Research, Liverpool, NSW, Australia. ${ }^{7}$ Woolcock Institute of Medical Research, University of Sydney, Sydney, NSW, Australia. ${ }^{8}$ Centenary Institute of Cancer Medicine \& Cell Biology, University of Sydney, Sydney, NSW, Australia. ${ }^{9}$ School of Public Health and Menzies Centre for Health Policy, University of Sydney, Sydney, NSW, Australia. ${ }^{10}$ Nutrition Policy Institute, University of California, College of Agriculture and Natural Resources, Berkeley, California, USA. "11 Sydney Local Health District, Sydney, NSW, Australia. ${ }^{12}$ Department of Respiratory Medicine, Liverpool Hospital, Liverpool, NSW, Australia.

\section{Received: 30 November 2017 Accepted: 25 February 2018} Published online: 27 March 2018

\section{References}

1. Gruzieva O, Bellander T, Eneroth K, Kull I, Melen E, Nordling E, et al. Trafficrelated air pollution and development of allergic sensitization in children during the first 8 years of life. J Allergy Clin Immunol. 2012;129(1):240-6.

2. Morgenstern V, Zutavern A, Cyrys J, Brockow I, Koletzko S, Kramer U, et al. Atopic diseases, allergic sensitization, and exposure to traffic-related air pollution in children. Am J Respir Crit Care Med. 2008;177(12):1331-7.

3. Brauer M, Hoek G, Smit HA, de Jongste JC, Gerritsen J, Postma DS, et al. Air pollution and development of asthma, allergy and infections in a birth cohort. Eur Respir J. 2007;29(5):879-88.

4. Gruzieva O, Gehring U, Aalberse R, Agius R, Beelen R, Behrendt $H$, et al. Meta-analysis of air pollution exposure association with allergic sensitization in European birth cohorts. J Allergy Clin Immunol. 2014;133(3):767-76. e7

5. Calder PC. Marine omega-3 fatty acids and inflammatory processes: effects, mechanisms and clinical relevance. Biochim Biophys Acta. 2015;1851(4):469-84

6. Bisgaard $\mathrm{H}$, Bonnelykke $\mathrm{K}$. Fish oil in pregnancy and asthma in offspring. $\mathrm{N}$ Engl J Med. 2017:376(12):1191-2.

7. Toelle BG, Ng KK, Crisafulli D, Belousova EG, Almqvist C, Webb K, et al. Eightyear outcomes of the childhood asthma prevention study. J Allergy Clin Immunol. 2010:126(2):388-9. 9.e1-3

8. Palmer DJ, Sullivan T, Gold MS, Prescott SL, Heddle R, Gibson RA, et al. Randomized controlled trial of fish oil supplementation in pregnancy on childhood allergies. Allergy. 2013;68(11):1370-6.

9. Anandan C, Nurmatov U, Sheikh A. Omega 3 and 6 oils for primary prevention of allergic disease: systematic review and meta-analysis. Allergy. 2009;64(6):840-8.

10. Klemens CM, Berman DR, Mozurkewich EL. The effect of perinatal omega-3 fatty acid supplementation on inflammatory markers and allergic diseases: a systematic review. BJOG. 2011;118(8):916-25.

11. Yang $H$, Xun $P$, He K. Fish and fish oil intake in relation to risk of asthma: a systematic review and meta-analysis. PLoS One. 2013:8(11):e80048.

12. Kremmyda LS, Vlachava M, Noakes PS, Diaper ND, Miles EA, Calder PC. Atopy risk in infants and children in relation to early exposure to fish, oily fish, or long-chain omega-3 fatty acids: a systematic review. Clin Rev Allergy Immunol. 2011;41(1):36-66.

13. Gunaratne AW, Makrides M, Collins CT. Maternal prenatal and/or postnatal n-3 long chain polyunsaturated fatty acids (LCPUFA) supplementation for preventing allergies in early childhood. Cochrane Database Syst Rev. 2015;7:Cd010085.

14. Mihrshahi S, Peat JK, Webb K, Tovey ER, Marks GB, Mellis CM, et al. The childhood asthma prevention study (CAPS): design and research protocol of a randomized trial for the primary prevention of asthma. Control Clin Trials. 2001;22(3):333-54

15. Marks GB, Mihrshahi S, Kemp AS, Tovey ER, Webb K, Almqvist C, et al. Prevention of asthma during the first 5 years of life: a randomized controlled trial. J Allergy Clin Immunol. 2006;118(1):53-61.

16. Hansell AL, Rose N, Cowie CT, Belousova EG, Bakolis I, Ng K, et al. Weighted road density and allergic disease in children at high risk of developing asthma. PLoS One. 2014;9(6):e98978.

17. Rose N, Cowie C, Gillett R, Marks GB. Weighted road density: a simple way of assigning traffic-related air pollution exposure. Atmos Environ. 2009; 43(32):5009-14.

18. Panel HEl. HEl. Traffic-Related Air Pollution: A Critical Review of the Literature on Emissions, Exposure and Health Effects. HEI Special Report 17. http://pubs.healtheffects.org/getfile.php?u=553. 17. 2010. Boston, MA, Health Effects Insitute. 2017.

19. Zou G. A modified poisson regression approach to prospective studies with binary data. Am J Epidemiol. 2004;159(7):702-6.
20. Miles EA, Calder PC. Omega- 6 and omega-3 polyunsaturated fatty acids and allergic diseases in infancy and childhood. Curr Pharm Des. 2014;20(6):946-53.

21. Barnig C, Levy BD. Innate immunity is a key factor for the resolution of inflammation in asthma. Eur Respir Rev. 2015:24(135):141-53.

22. Magnusson J, Kull I, Westman M, Hakansson N, Wolk A, Melen E, et al. Fish and polyunsaturated fat intake and development of allergic and nonallergic rhinitis. J Allergy Clin Immunol. 2015;136(5):1247-53. e1-2

23. Malan L, Baumgartner J, Calder PC, Zimmermann MB, Smuts CM. N-3 longchain PUFAs reduce respiratory morbidity caused by iron supplementation in iron-deficient south African schoolchildren: a randomized, double-blind, placebo-controlled intervention. Am J Clin Nutr. 2015;101(3):668-79.

24. Mischke M, Plosch T. More than just a gut instinct-the potential interplay between a baby's nutrition, its gut microbiome, and the epigenome. Am Physiol Regul Integr Comp Physiol. 2013;304(12):R1065-9.

25. Myles IA, Pincus NB, Fontecilla NM, Datta SK. Effects of parental omega-3 fatty acid intake on offspring microbiome and immunity. PLoS One. 2014; 9(1):e87181.

26. Ji H, Biagini Myers JM, Brandt EB, Brokamp C, Ryan PH, Khurana Hershey GK. Air pollution, epigenetics, and asthma. Allergy, asthma, and clinical immunology : official journal of the Canadian Society of Allergy and. Clin Immunol. 2016;12:51.

27. Yang IV, Lozupone CA, Schwartz DA. The environment, epigenome, and asthma. J Allergy Clin Immunol. 2017;140(1):14-23.

28. Zheng $Y$, Sanchez-Guerra M, Zhang Z, Joyce BT, Zhong J, Kresovich JK, et al. Traffic-derived particulate matter exposure and histone $\mathrm{H} 3$ modification: a repeated measures study. Environ Res. 2017:153:112-9.

29. Rahbar E, Ainsworth HC, Howard TD, Hawkins GA, Ruczinski I, Mathias R, et al. Uncovering the DNA methylation landscape in key regulatory regions within the FADS cluster. PLoS One. 2017;12(9):e0180903.

30. Hoile SP, Clarke-Harris R, Huang RC, Calder PC, Mori TA, Beilin L, et al. Supplementation with N-3 long-chain polyunsaturated fatty acids or olive oil in men and women with renal disease induces differential changes in the DNA methylation of FADS2 and ELOVL5 in peripheral blood mononuclear cells. PLoS One. 2014;9(10):e109896.

31. Hussey B, Lindley MR, Mastana SS. Omega 3 fatty acids, infalmmation and DNA. Clin Lipidol. 2017;12(1):24-32.

32. Lee HS, Barraza-Villarreal A, Hernandez-Vargas H, Sly PD, Biessy C, Ramakrishnan $U$, et al. Modulation of DNA methylation states and infant immune system by dietary supplementation with omega-3 PUFA during pregnancy in an intervention study. Am J Clin Nutr. 2013;98(2):480-7.

33. Diaz-Sanchez D, Garcia MP, Wang M, Jyrala M, Saxon A. Nasal challenge with diesel exhaust particles can induce sensitization to a neoallergen in the human mucosa. J Allergy Clin Immunol. 1999;104(6):1183-8.

34. Granell R, Henderson AJ, Sterne JA. Associations of wheezing phenotypes with late asthma outcomes in the Avon longitudinal study of parents and children: a population-based birth cohort. J Allergy Clin Immunol. 2016; 138(4):1060-70.

35. Morgan WJ, Stern DA, Sherrill DL, Guerra S, Holberg CJ, Guilbert TW, et al. Outcome of asthma and wheezing in the first 6 years of life: follow-up through adolescence. Am J Respir Crit Care Med. 2005;172(10):1253-8. 